\title{
EVALUATION OF THE RATIONALITY OF PSYCHOTROPIC DRUG PROMOTIONAL LITERATURES IN NEPAL
}

\author{
Sah Phoolgen ${ }^{1},{ }^{\text {SSah Ajit Kumar }}{ }^{2}$, Jha Rajesh Kumar ${ }^{3}$ \\ LecturerDepartment of Pharmacology, Chitwan School of Medical Sciences, Bharatpur-10, Chitwan, Nepal \\ *Corresponding author's Email: drajit42@gmail.com
}

Received 19 Sep 2012; Review Completed 27 Sep 2012; Accepted 17 Oct 2012, Available online 15 Nov 2012

\begin{abstract}
Major marketing tool used by pharmaceutical companies in the Nepal is direct-to-healthcare professional marketing utilizing promotional drug information brochures. The aim was to investigate whether the information in promotional brochures presented to healthcare professionals in the Nepal by pharmaceutical representatives complied with the World Health Organization (WHO) criteria for brochures. This observational, cross-sectional study was conducted in the Psychiatric outpatient department (OPD) of a tertiary care hospital at Bharatpur, Chitwan, Nepal. A total of seventy one drugs promotional brochures were analyzed according to the WHO Guidelines during the study period. General information like name(s) of the active ingredient(s) using either international nonproprietary names (INN) or the approved generic name of the drug was mentioned on most of advertisements $(n=62,87.32 \%)$. Only $88.73 \%(n=63)$ brochure contained amount of active ingredient(s) per dosage form while none of the brochure contained other ingredients known to cause problems. Approved therapeutic indications and safety profile like side effects or major adverse drug reactions were outlined in $83.10 \%$ $(n=59)$ and $11.27 \%(n=8)$ of promotional drug brochures respectively. This study highlights the need of healthcare professionals in the Nepal to remain cautious about promotional material presented by pharmaceutical representatives.

Keywords: brochures; evaluation; pharmaceutical; promotional.
\end{abstract}

\section{INTRODUCTION:}

Drug promotion refers to all the information and persuasive activities by manufacturers and distributors in order to induce the prescription, supply, purchase and/or use of medicinal drugs. There is evidence that drug utilization problems are increasingly encountered in many developing countries due to unethical practices of pharmaceutical promotion.

According to the World Health Organization (WHO), medicinal drug promotion should be reliable, accurate, truthful, informative, balanced, up-to-date and capable of substantiation. Text and illustration contents should be consistent with scientific information. ${ }^{1}$ Pharmaceutical companies are in the business of developing and selling new drugs. These are accepted in health care system through health care professionals, and its availability is of little value unless the prescriber is aware of its existence and has scientific information to use it effectively. ${ }^{2}$ The pharmaceutical industry in US spent over $\$ 11$ billion in pharmaceutical marketing, excluding medication samples, in 2004, with more than $\$ 7$ billion directed to clinicians. ${ }^{3}$

Drug advertisement is an effective tool to form physicians' perception of drug efficacy and prescription behavior. ${ }^{4-7}$ Advertisement claims of pharmaceutical companies have been criticized for making exaggerated claims, emphasizing relative over absolute effect measures, ${ }^{8}$ omission of adverse effects, and for use of different standards for promoting drugs in resourcelimited countries. ${ }^{9}$ Pharmaceutical sales representatives (medical representatives) frequently visit $70 \%$ to $90 \%$ of physicians during their daily clinical practice and many consider the promotional printed material to be a major source of clinical information. ${ }^{10}$

One of the well-known promotional activities of pharmaceutical industries is to produce advertising brochures which at times are inaccurate and of poor educational value. ${ }^{9,11,12}$ These promotional activities create the potential for inappropriate prescribing practices by influencing physicians' prescribing behavior without necessarily benefiting the patients ${ }^{13-15}$ but contributes to increased health care costs. ${ }^{16}$ Non-ethical medicinal drug promotion is a major issue worldwide leading to irrational drug use, overprescription, self-medication and drug abuse. ${ }^{7,17,18}$ This is a more serious issue in developing countries.

This study was conducted to find out the accuracy of promotional drug literature presented to prescribers by using "WHO criteria for ethical medicinal drug promotion, 1988". ${ }^{1}$

\section{MATERIAL AND METHODS:}

This observational, cross-sectional study was conducted in the Psychiatric outpatient department (OPD) of Chitwan School of Medical Sciences, a tertiary care hospital at Bharatpur, Chitwan, Nepal, after its approval by Institutional Ethics Committee. More than hundred fifty of brochures were collected from the period $1^{\text {st }}$ February 2011 to $31^{\text {st }}$ July 2011. Collected brochures were then explored to exclude the following materials: Literature promoting medicinal devices and equipments, ayurvedic medicines, drug monographs, reminder advertisements (reminder advertisements do not present 
any therapeutic information and have different criteria for evaluation). ${ }^{1}$

WHO criteria for ethical medicinal drug promotion dictate that promotional literature should contain the following informations. ${ }^{1}$

1. The name(s) of the active ingredient(s) using either international nonproprietary names (INN) or the approved generic name of the drug.

2. The brand name

3. Amount of active ingredient(s) per dose

4. Other ingredients known to cause problems, i.e. adjuvant

5. Approved therapeutic uses

6. Dosage form or dosage schedule

7. Side effects and major adverse drug reactions,
8. Precautions, contraindications and warnings,

9. Major drug interactions

10. Name and address of manufacturer or distributor

11. Reference to scientific literature as appropriate

\section{RESULTS:}

A total of seventy one drug promotional brochures were evaluated from different manufacturers. The majority of promotional materials were from Indian companies or multinational companies based in India. The manufacturer's name was not mentioned in eleven (15.50 $\%)$ of the promotional materials. The therapeutic classifications of the drugs promoted in the promotional material are mentioned in Table 1 and analysis of the pharmaceutical information present in the promotional materials is described in Table 2 .

Table 1: Therapeutic groups of the drugs

\begin{tabular}{|c|c|c|c|c|c|}
\hline \multirow{2}{*}{$\begin{array}{l}\text { Anti - } \\
\text { depressant }\end{array}$} & Venlafaxine & Escitalopram & Fluoxetine & Sertraline & \multirow[t]{2}{*}{ Mitrazapine } \\
\hline & Amitriptyline & Olanzapine & Imipramine & Paroxetine & \\
\hline Anti - & \multicolumn{2}{|c|}{ Sodium valproate and valproic acid } & Clonazepam & Lamotrigene & Levetiracetam \\
\hline convulsant & Carbamazepine & Quetiapine & Pregabaline & & \\
\hline Anti-psychotic & Risperidone & Aripiprazole & Lithium carbonate & & \\
\hline Others & Donepezil & Flunarazine & & & \\
\hline
\end{tabular}

Table 2: Availability of pharmaceutical information in the promotional materials

\begin{tabular}{|l|c|c|}
\hline WHO criteria for ethical medicinal drug promotion & Psychotropic Agents & \% age \\
\hline $\begin{array}{l}\text { 1. The name(s) of the active ingredient(s) using either international nonproprietary } \\
\text { names (INN) or the approved generic name of the drug. }\end{array}$ & 62 & 87.32 \\
\hline 2. The brand name & 71 & 100 \\
\hline 3. Amount of active ingredient(s) per dosage form & 63 & 88.73 \\
\hline 4. Other ingredients known to cause problems, i.e. adjuvant & 0 & 0 \\
\hline 5. Dosage form or dosage schedule & 55 & 77.46 \\
\hline 6. Approved therapeutic uses & 59 & 83.10 \\
\hline 7. Side effects and major adverse drug reactions & 8 & 11.27 \\
\hline 8. Precautions, contraindications and warnings & 7 & 9.86 \\
\hline 9. Major drug interactions & 6 & 8.45 \\
\hline 10. Name and address of manufacturer or distributor & 60 & 84.50 \\
\hline 11. Reference to scientific literature as appropriate & 9 & 12.67 \\
\hline
\end{tabular}

\section{DISCUSSION:}

It was found from this study that there are deficiencies in drug information of the advertised drugs in Nepal. Pharmaceutical industries did not follow WHO guidelines while promoting their drug products, thus accelerated their commercial motive rather than ethical educational aspect. The promotional brochures were full of unsubstantiated claims regarding safety or efficacy, and those claims were therapeutically irrelevant also. Important informations regarding adverse drug reactions, contraindications, or drug interactions were usually missing. Reference citations were given to earn credibility, but it was difficult to trust them because of ambiguous presentation, poor quality, and questionable retrievability. Therapeutically unrelated matter was printed, compromising the space to be given to important brief prescription information.
In this study, general information like name(s) of the active ingredient(s) using either international nonproprietary names (INN) or the approved generic name of the drug was mentioned on most of advertisements $(n=62,87.32 \%)$, This was a similar finding to the study performed in Nepal ${ }^{19}$, Thailand ( $88 \%){ }^{20}$ This study showed that the among the entire advertisements only $88.73 \% \quad(n=63)$ brochure contained amount of active ingredient(s) per dosage form which is slightly higher than the study which contained $81.82 \%{ }^{19}$ while none of the brochure contained other ingredients known to cause problems. In another study of the advertising material and marketing brochures sent out by drug companies to physician in Pakistan also showed about only $4 \%$ brochures contained the information. ${ }^{21}$ In the similar studies performed in western Nepal none of the promotional brochure has other ingredients known to cause problems. 
Likewise, in this study, approved therapeutic indications and safety profile like side effects or major adverse drug reactions were outlined in $83.10 \%(n=59)$ and $11.27 \%$ $(n=8)$ of promotional drug brochures respectively where indications are similar to the studies in Laos (100\%), Thailand (91.2\%), Vietnam $(86.4 \%){ }^{20}$ and Pakistan $(86.95 \%)^{21}$ while the safety profile is much less compared to the studies in Laos (39.2\%), Thailand (43.6\%), Vietnam $(55.6 \%)^{20}$ and Pakistan (47.82). ${ }^{21}$

Drugs promotion brochure containing dosage form and manufacture's name and address in our study were observed to be $77.46 \% \quad(n=55)$ and $84.50 \% \quad(n=60)$ respectively, which is comparatively higher than the studies observed in Laos [dosage form (56.1\%), manufacturer name $(39.2 \%)$ ], Thailand [dosage form $(59 \%)$, manufacturer name $(76.2 \%){ }^{20}$ and Pakistan. $^{21}$

The enormity of inappropriate drug advertisement is likely to be higher in developing countries, where policy on drug advertisement is weak and the appropriate structures to monitor advertisement are lacking. In Nepal where drug advertisement guidelines are similar to those of WHO, deviation from the guidelines was quite obvious in this study. This deviation may have resulted from weakness in implementing drug advertisement policy in Nepal by the department of drug administration (DDA) and lack of mechanism to monitor drug promotional campaign by the pharmaceutical companies.

Drug advertisement with inadequate information for appropriate prescribing contradicts the policy of

\section{REFERENCES:}

1. Ethical criteria for medicinal drug promotion. World Health Organization [Online]. 1988 May 13; [8 screens].

2. Stimson GV. Information contained in drug advertisements. BMJ 1975;4:508-9.

3. Health IMS: Total U.S. promotional spend by type, 2004. 2005 [http://www.imshealth.com/ims/portal/front/articleC/0,2777,6599_49 695992_75406357,00.html]

4. Beary JF 3rd: Pharmaceutical marketing has real and proven value. Characteristics of materials distributed by drug companies: four points of view. J Gen Intern Med 1996, 11:635-6.

5. Levy R: The role and value of pharmaceutical marketing. Arch Fam Med 1994, 3:327-32.

6. Wolfe S: Drug advertisements that go straight to the hippocampus Lancet 1996, 348:632.

7. Avorn J, Chen M, Hartley R: Scientific versus commercial sources of influence on the prescribing behavior of physicians. Am J Med 1982,73:4-8.

8. Bucher HC, Weinbacher M, Gyr K: Influence of method of reporting study results on decision of physicians to prescribe drugs to lower cholesterol concentration. BMJ 1994, 309:761-4.

9. Villanueva P, Peiro S, Librero J. et al. Accuracy of pharmaceutical advertisements in medical journals. Lancet 2003,361:27-32.

10. Mejía R, Avalos A. Printed material distributed by pharmaceutical propaganda agents Medicina (B Aires). 2001;61(3):315-8.

11. Loke TW, Koh FC, Ward JE. Pharmaceutical advertisement claims in Australian medical publications: Is evidence accessible, compelling and communicated comprehensively? Med J Aust. 2002;177(6):291-3.

12. Rohra DK, Gilani AH, Memon IK, et al. Critical evaluation of claims made by pharmaceutical companies in drug promotional material in Pakistan. J Pharm PharmaceutSc.i 2006;9:50-9.

13. Brody H. The company we keep: Why physicians should refuse to see pharmaceutical representatives. Ann Fam Med 2005;3:82-5

14. Orlowski JP, Wateska L. The effects of pharmaceutical firm enticements on physician prescribing patterns. There's no such thing as a free lunch. Chest 1992;102:270-3. pharmaceutical companies. ${ }^{22}$ The lack of training of neurophysicians in evaluating drug adverts for appropriate prescribing information could lead to inappropriate prescribing. The lack of serious sanctions is a feature of self-regulatory systems of advertising control. ${ }^{23}$ Ironically, misleading drug promotion has appeared to be a vicious circle between the drug companies and health professionals that does more harm than good worldwide. ${ }^{24}$ Various studies reported variable rates of misleading claims in the printed promotional materials. The time needed for the individual doctor to critically appraise the advertised drug is usually not available and they may lack the skills required. ${ }^{12}$ Therefore, formal teaching of doctors in their undergraduate training in pharmacology, in the art of critical appraisal of drug advertisement needs to be addressed.

\section{CONCLUSION:}

From this study it is concluded that none of the promotional material in Nepal exactly follows the WHO's Ethical Criteria for Medicinal Drug Promotion. Safety profile like side effects or major adverse drug reactions, precautions, major drug interactions are missing from most of the promotional materials. Pharmaceutical advertisements subtly influence the prescribing behavior of health providers and therefore affect the end user of these drugs, the patient.

15. Wazana A. Physicians and the pharmaceutical industry: Is a gift ever just a gift? JAMA 2000;283:373-80.

16. Cardarelli R, Licciardone JC, Taylor LG. A cross-sectional evidence-based review of pharmaceutical promotional marketing brochures and their underling studies: Is what they tell us important and true? BMCFamPrat. 2006;3(7):13.

17. Hogerzeil HV. Promoting rational prescribing: an international perspective. Br J ClinPharmacol. 1995;39(1):1-6.

18. Kessler DA, Pines WL. The federal regulation of prescription drug advertisement and promotion. JAMA. 1990;264(18):2409-15.

19. Alam K, Shah AK, OjhaP.et al. Evaluation of drug promotional materials in a hospital setting in Nepal. Southern Med Review. 2009;2(1):2-6.

20. Angsulee NK. A participatory evaluation of the implementation of WHO's ethical criteria for medical drug promotion in multiple countries. Final Report, 2004.

21. Vakani1 F, Naqvi K, Amin A. Content audit of drug advertisements in Pakistan. Indian J of Med Ethics 2011;8(3):167-9.

22. Vlassov V, Mansfield P, Lexchin J, et al. Do drug advertisements in Russian medical journals provide essential information for safe prescribing? West J Med. 2001;174:391-4.

23. Lexchin J, Kawachi I. The self-regulation of pharmaceutical marketing: initiatives for reform. In: Contested Ground: Public Purpose and Private Interest in the Regulation of Prescription Drugs. Ed: Davis P. New York: Oxford University Press; 1996:221-235.

24. Gully K. The big issue? Estimating the prevalence of childhood overweight and obesity in Wales (MPH Dissertation). Cardiff University, December 2004. 